NASA Technical Memorandum 102141

\title{
Development and Testing of a 20-kHz Component Test Bed
}

Robert M. Button

National Aeronautics and Space Administration

Lewis Research Center

Cleveland, Ohio

Andrew S. Brush

Sverdrup Technology, Inc.

NASA Lewis Research Center Group

Cleveland, Ohio

and

Richard C. Sundberg

General Dynamics Corporation

Space Sustems Division

(MASA-TH-102141) DEVELCPEEAT AAD TESTING OP $\triangle$ 20-kHz COAFCAEMI TEST BEC (MASA. Lenis besearch Center) \& p CSCL 09C

บ89-2ฐ403

rrepared lor the

Unclas

G3/33 0219891

24th Intersociety Energy Conversion Engineering Conference cosponsored by the IEEE, AIAA, ANS, ASME, SAE, ACS, and AIChE Washington, D.C., August 6-11, 1989 


\section{DEVELOPMENT AND TESTING OF A $20-\mathrm{kHz}$ COMPONENT TEST BED}

\author{
Robert M. Button \\ National Aeronautics and Space Administration \\ Lewis Research Center \\ Cleveland, $\mathrm{OH} 44135$
}

\author{
Andrew S. Brush \\ Sverdrup Technology, Inc. \\ NASA Lewis Research Center Group \\ Cleveland, $\mathrm{OH} 44135$
}

\author{
Richard C. Sundberg \\ General Dynamics Corporation \\ Space Systems Division \\ San Diego, CA 92138
}

\begin{abstract}
A history of the General Dynamics Space Systems Division $20 \mathrm{kHz}$ Breadboard is presented including its current configuration and its role in the SSF program. Highlights and results are presented on a series of tests conducted on the $20 \mathrm{kHz}$ Breadboard. The first test presented is the $20 \mathrm{kHz}$ Breadboard Acceptance test. This test verified the operation of the delivered Breadboard and also characterized the main components of the system. Next, an in-depth efficiency testing effort is presented. The tests allempled to apportion all the power losses in the $20 \mathrm{kHz}$ Breadboard Main Inverter Units. Distortion test dala is presented showing the distortion characteristics of a Mapham inverter. Lastly, current work on the $20 \mathrm{kHz}$ Breadhoard is presented including Main Inverter Unit paralleling tests. Conclusions are summarized and references given.
\end{abstract}

\subsection{INTRODUCTION}

Since 1984, NASA and its partner contractors have been defining and designing a permanently orbiting space facility known as Space Station Freedom. The Space Station program was broken down into four major Work Packages. The Lewis Research Center was awarded Work Package 4; the definition, development, and testing of the Electrical Power System (EPS). During a three year Phase $B$ definition effort, engineers at Lewis conducted an extensive Irade study to determine the optimal power system for space applications. The power system had to be solar powered and provide a total power output to the users of $75 \mathrm{~kW}$. A distribution system trade study between $150 \mathrm{Vdc}$, $440 \mathrm{Vac}-400 \mathrm{~Hz}$, and $440 \mathrm{Vac}-20 \mathrm{kHz}$ was conducted. It was concluded that a $440 \mathrm{Vac}-20 \mathrm{kHz}$ power distribution system would be optimally lightweight and have minimal electromagnetic interference (EMI) at low frequencies $(<1 \mathrm{kHz})[1]$.

An Advanced Development program was initiated so that $20 \mathrm{kHz}$ power component technology could be developed ahead of the prime program, thereby reducing program risk. The components developed included: a rotary power transfer device (roll ring), high power semiconductors (MCTs) and semiconductor packages, power cables and connectors, $20 \mathrm{kHz}$ transformers, and remote power controllers (RPCs) [2].

In a separate contract initiated by Lewis, a $20 \mathrm{kHz}$ Breadboard was designed and built by General Dynamics Space Systems Division [3]. Its purpose was to demonstrate the feasibility of a $20 \mathrm{kHz}$ distribution system and to provide an initial test bed for $20 \mathrm{kHz}$ technology. The Breadboard consists of: three $20 \mathrm{kHz}$ Main Inverter Units
(MIUs), two types of $20 \mathrm{kHz}$ optimized transmission lines, and three types of load converters. The $20 \mathrm{kHz}$ Breadboard components are described in Section 2.

The first set of tests presented are acceptance tests that were conducted to checkout and evaluate the Breadboard under steady state conditions. All major components were tested for: general operation, maximum power output, efficiency, and load regulation [4]. The results of the acceptance tests are summarized in Section 3.

The second set of tests conducted were detailed efficiency measurements of an MIU. Total power loss in an MIU was apportioned to various MIU power components. Results from these tests are summarized in Section 4.

The third sel of tests describe MIU output tolal harmonic distortion (THD). THD was characterized as a function of clocking frequency and output voltage setpoint. An optimal operating condition for a split inductor Mapham inverter was also identified. Results from these tests are summarized in Section 5.

Finally, initial tests characterizing inverter paralleling and power sharing were conducted al Lewis. A summary of the preliminary results are presented in Section 6 .

\subsection{THE GDSSD $20 \mathrm{kHz}$ BREADBOARD}

The GDSSD $20 \mathrm{kHz}$ Breadboard was installed in the Power Management and Distribution Photovollaic (PMAD/PV) test bed in May 1987. A block diagram of the test bed is shown in Figure 2.1. The test bed supplies DC power to the $20 \mathrm{kHz}$ Breadboard and also provides various loads for lesting.

\subsection{Main Inverter Units}

The main test articles in the GDSSD $20 \mathrm{kHz}$ Breadboard are the three $20 \mathrm{kHz}$ Main Inverter Units. Each MIU is rated $8.3 \mathrm{~kW}$ at $440 \mathrm{Vac}$ for a total power capability of $25 \mathrm{~kW}$ when all three are paralleled. Each MIU consists of two Mapham series resonant inverters utilizing a split resonant inductor (Figure 2.2). The switches are "hockey puck" SCRs and the flyback diodes allow bidirectional current flow through each leg. Also, snubber circuits are installed to prevent inadvertent SCR turn on. A short description of the Mapham inverter operation can be found in Mapham[5].

The two Mapham inverters are connected in series through an output transformer. The series connection allows for closed-loop phasor regulation of the output voltage. As the difference of the switch firing angle between the two inverters is increased, the output voltage of the MIU decreases. This firing angle difference is defined as the regulation angle. The transformer also provides for load isolation and output voltage magnitude selection. 


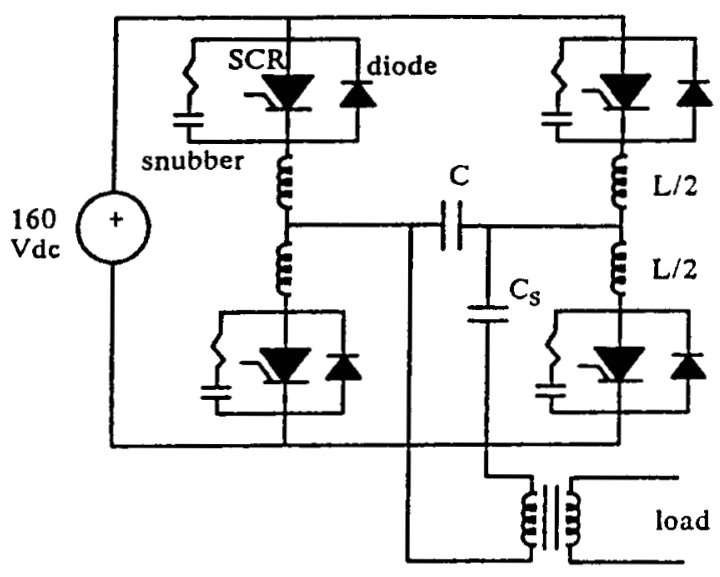

Figure 2.2 Mapham Series Resonant Inverter

\subsection{Transmission Cable}

Two types of transmission cable have been specifically designed for $20 \mathrm{kHz}$ power under the Advanced Development program. Both designs feature a "flat coaxial" layout. A center conductor (supply) is sandwiched between two wider conductors (returns) creating a shielded cable (Figure 2.3 ). This reduces radiated electromagnetic interference (EMI) by providing electric field shielding and reduced magnetic fields. Both designs also employ a small cross sectional area which reduces the skin effect resistance of $\mathrm{AC}$ current at $20 \mathrm{kHz}$.

The flat Litz cable made by Induction General is constructed of three flat conductors. Each conductor is a braided strap of Litz wire. The Litz wire reduces the AC resistance of the cabie by providing many current paths along wire with a small cross sectional area $[6]$.

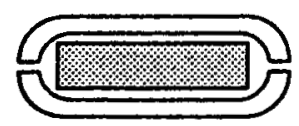

Litz Cable

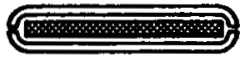

Gore Cable
Figure 2.3 - Cross Section of $20 \mathrm{kHz}$ Cable

The Gore cable, made by W. L. Gore Inc., uses thin, flat copper conductors to reduce the cross sectional area of the cable. The thin copper conductors provide greater flexibility than the Litz cable making it a better design for space applications where packaging and deployment of cable must be minimized. The Gore cable achieves a lower series inductance by reducing the current loop to a minimum. However, this also results in a higher capacitance compared to that of the Litz cable.

\subsection{Load Converter}

The DC load converter converts $440 \mathrm{Vac}-20 \mathrm{kHz}$ to a variable output $D C$ voltage of $25-150 \mathrm{Vdc}$. The converter is a slandard transformer rectifier using SCRs as the power switches (Figure 2.4). Its output voltage is phase regulated by delaying the conduction period of the rectifier SCRs. The output is low-pass filtered to reduce ripple. The load converter is capable of delivering $5 \mathrm{~kW}$ at $150 \mathrm{Vdc}$ to the loads.

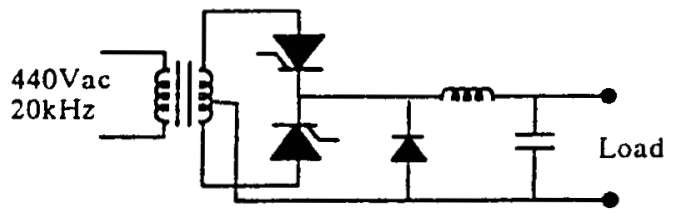

Figure 2.4 - DC Load Converter

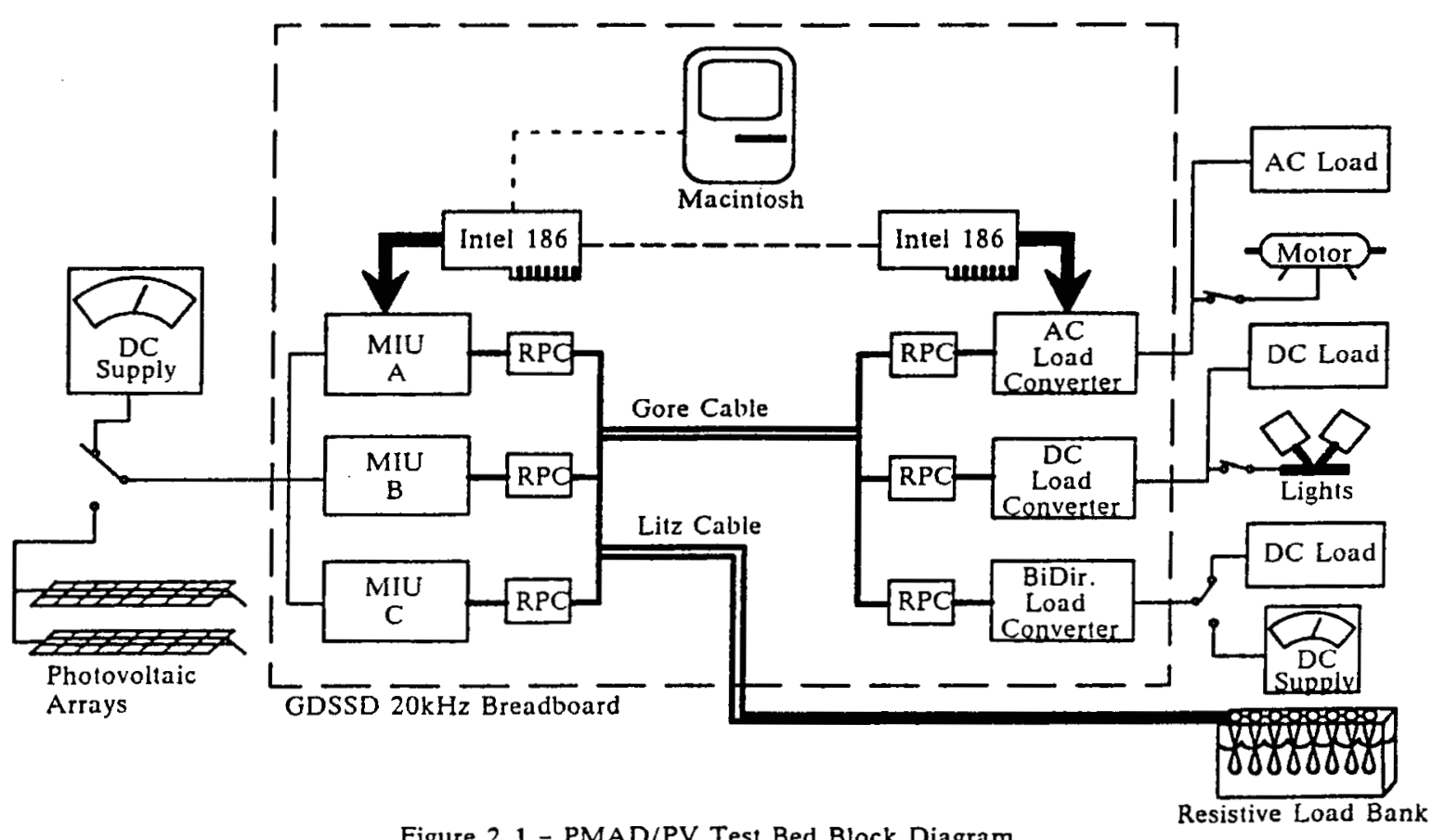




\subsection{AC Load Converter}

The AC load converter converts the $20 \mathrm{kHz}$ line voltage to variable voltage $(25-120 \mathrm{Vrms})$, variable frequency (13-3300 Hz), three phase $A C$ power. The low frequency $A C$ voltage waveform is constructed using three $A C$ to $D C$ converters (one for each phase). Each converter is a bridge which is capable of producing periods of positive, zero, and negative rectified $A C$. The three converters are phase shifted 120 and 240 degrees to produce a line-to-line six-step AC voltage. This six-step waveform is then output filtered to produce a smooth $A C$ waveform. The $A C$ converter is capable of providing $25 \mathrm{~kW}$ of low frequency AC power.

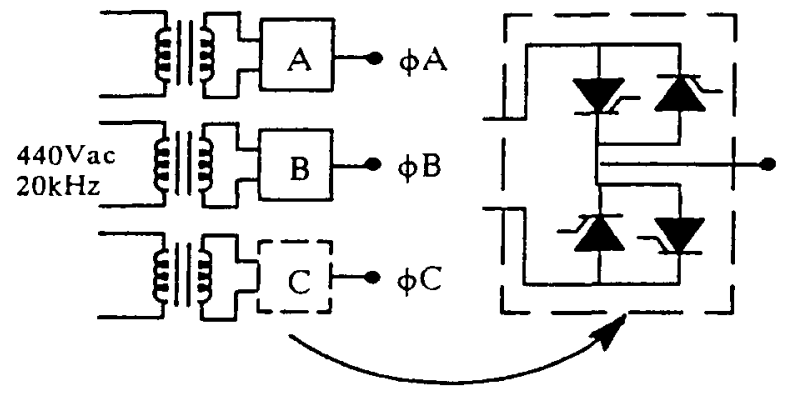

Figure 2.5 - AC Load Converter

\subsection{Bidirectional Load Converter}

The bidirectional load converter is a prototype concept of a baltery charge/discharge unit (BCDU). Essentially, it is an MIU which can be configured into a DC load converter (Fig. 2.6). In the "converter" mode, $20 \mathrm{kHz}$ power is converted into DC power through the inverter's resonant tank and SCR switches. In this mode, it is rated for $5 \mathrm{~kW}$ at $150 \mathrm{Vdc}$. In the "driver" mode the converter works as an MIU, converting $150 \mathrm{Vdc}$ to $440 \mathrm{Vac}-20 \mathrm{kHz}$. As an MIU, it is rated at $10 \mathrm{~kW}$ at $440 \mathrm{Vac}$.

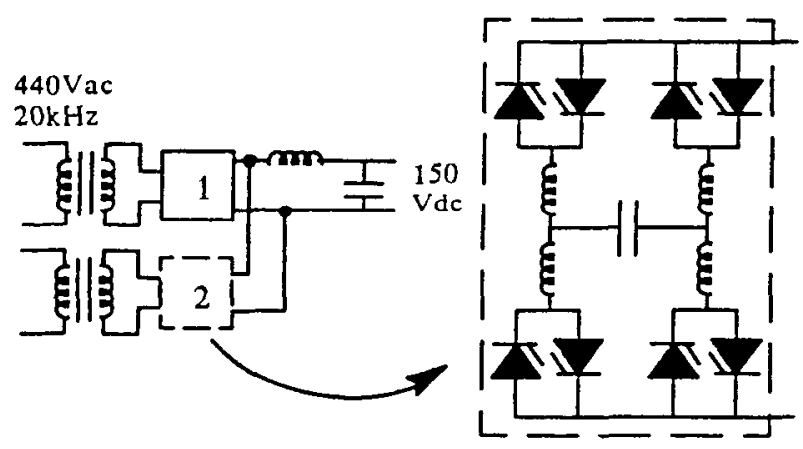

Figure 2.6 - Bidirectional Load Converter

\section{$3.020 \mathrm{kHz}$ BREADBOARD ACCEPTANCE TEST}

This section presents highlights of the initial acceptance lests performed on the General Dynamics Space Systems Division $20 \mathrm{kHz}$ Breadboard. General characteristics of the components are given such as load regulation and efficiency.

\subsection{MIU Performance}

Each of the three MIUs were tested individually, and each one operated up to rated power $(8.3 \mathrm{~kW})$. The three
MIUs were also paralleled and loaded up to $22 \mathrm{~kW}$; a test bed load bank limitation at the time. Since then, a total power output of $28 \mathrm{~kW}$ paralleled and $12 \mathrm{~kW}$ individually has been achieved using a resistive load bank. The MIUs each had a maximum efficiency of $87 \%$ at full rated power (8. $3 \mathrm{~kW})$.

The inverters were also tested for their load voltage regulation. The inverters were loaded by the load converters at varying power levels and phases from about $100 \mathrm{~W}$ up to $8.3 \mathrm{~kW}$. Maximum and minimum vollage points and percent regulation are shown in Figure 3.1.

\begin{tabular}{c|c|c|c} 
MIU & Low Vac & High Vac & $\%$ Regulation \\
\hline A & 441.0 & 450.7 & $+/-1.1 \%$ \\
B & 440.5 & 451.1 & $+1-1.2 \%$ \\
C & 437.0 & 451.8 & $+/-1.6 \%$
\end{tabular}

Figure 3.1 - Inverter Load Voltage Regulation

\subsection{Load Converter Performance}

The DC load converter was tested up to $4.4 \mathrm{~kW}$ at $145 \mathrm{Vdc}$. The output voltage regulation was excellent and varied from $145.5 \mathrm{Vdc}$ at $0.16 \mathrm{~kW}$ to $144.8 \mathrm{Vdc}$ at $4.4 \mathrm{~kW}$ $(+i-0.25 \%$ regulation). The DC converter's efficiency was $89.4 \%$ at $4.4 \mathrm{~kW}$ and $145 \mathrm{Vdc}$.

\subsection{AC Load Converter Performance}

The AC load converter was tested up to $15 \mathrm{~kW}$ at $120 \mathrm{Vac}-60 \mathrm{~Hz}$. Maximum efficiency was $89.5 \%$ at $14 \mathrm{~kW}$ and 100 Vac output. Also, the load converter was tested at output frequencies of $60 \mathrm{~Hz}, 400 \mathrm{~Hz}$, and $1 \mathrm{kHz}$.

\subsection{Bidirectional Load Converter Performance}

The Bidirectional converter in the DC converter mode was also tested up to $4.2 \mathrm{~kW}$ at $140.5 \mathrm{Vdc}$. The output voltage varied from $143 \mathrm{Vdc}$ at $0.14 \mathrm{~kW}$ to $140.5 \mathrm{Vdc}$ at $4.2 \mathrm{~kW}(+1-0.9 \%$ regulation). Efficiency was $89 \%$ at $4.2 \mathrm{~kW}$ and $140 \mathrm{Vdc}$.

The Bidirectional converter in the inverter mode was tested up to $4.25 \mathrm{~kW}$ at $440 \mathrm{Vac}$. The DC load converter was used as a load, limiting the load capability to $4.25 \mathrm{~kW}$. The converter was also successfully paralleled with the three inverters.

\subsection{MIU EFFICIENCY TESTS}

In this test, MIU power components were instrumented to apportion power losses to each component. This was the groundwork for designing a second generation MIU with greater efficiency.

Instrumenting the components to measure power losses was the biggest challenge. The method used in all cases was to multiply the vollage drop across the device and the current through the device to obtain an instantaneous power curve. A Tektronix digital oscilloscope was used to do the waveform multiplication. The voltage drop across an SCR varied from $150 \mathrm{Vdc}$ (not conducting) to about $3 \mathrm{Vdc}$ (conducting). Since all the power loss occurs during conduction. a voltage limiter was built for the loss measurements. The voltage limiter limited voltage to the oscilloscope to $+/-15 \mathrm{~V}$ so that the voltage input would not become saturated at the higher voltage levels.

Efficiency was first measured on MIU B of the GDSSD $20 \mathrm{kHz}$ Breadboard. The DC input power was calculated by Volt-Amp multiplication of DC panel meters. The AC power out was measured by Clarke-Hess digital power meters. Both methods were checked against, and agreed with, the voltage-current multiplication method on 
the Tektronix oscilloscope. The results are summarized below.

$$
\begin{aligned}
& \text { DC Input Power : } 147.3 \mathrm{Vdc} \\
& \times \text { 85iLAde } \\
& 12538 \text { Watts }
\end{aligned}
$$

AC Outpul Power : 10950 Waus

Total Loss $=1588$ Watts

MIU Efficiency $=87.3 \%$

The individual components were measured for power loss using the Tektronix oscilloscope. The two lower SCRs, diodes, and snubbers on each Mapham inverter were measured and the results multiplied by two to account for the upper components. The loss through the transformer was also measured. Inductor and tank capacitor losses were approximated using results obtained at GDSSD. Similar capacitors and inductors were measured for power loss at GDSSD by immersing the components in an oil bath and measuring the temperature gradient as constant power was applied. The results are summarized below.

MIU Component Loss Measurements :

$\begin{array}{lrl}\text { SCRs } & 324.5 \mathrm{~W} \times 2 & =649 \mathrm{~W} \\ \text { Snubbers } & 98.8 \mathrm{~W} \times 2 & =198 \mathrm{~W} \\ \text { Diodes } & 25.5 \mathrm{~W} \times 2 & =51 \mathrm{~W} \\ \text { Transformer } & 45.0 \mathrm{~W} & =45 \mathrm{~W} \\ \text { Inductors } & 30 \mathrm{~W} \times 8 & =240 \mathrm{~W} \\ \text { Capacitors } & 30 \mathrm{~W} \times 2 & =60 \mathrm{~W} \\ & \text { TOTAL } & =1244 \mathrm{~W}\end{array}$

Losses unaccounted for $=344 \mathrm{~W}$

Total losses accounted for $=78.4 \%$

Some of the losses unaccounted for were attributed to unmeasured losses in the input filter capacitors, the output series capacitor, and unnecessary wiring losses in the cabinets. It has been reported that using improved snubbers and helter cable routing has increased efficiency of a similar SCR MIU to $91 \%$ [7].

Over half of the total losses were found in the SCRs and snubber circuitry. At the time, it was expected that high power transistors (IGBTs or MCTs) would replace the SCRs in a second generation MIU, thereby reducing switch and snuiber losses. This has recently been confirmed at GDSSD where advanced MIUs using IGBTs have shown an increase in efficiency over those using SCRs.

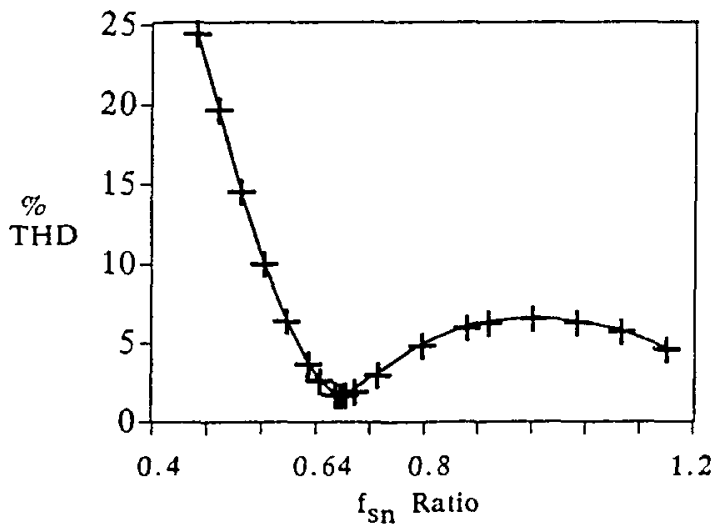

Figure 5.1 - Mapham Inverter THD vs. $f_{s n}$

\subsection{INVERTER DISTORTION TESTS}

In this section, summaries of two distortion tests are presented. Mapham inverter THD was first characterized with respect to switching frequency and an optimum switching frequency vs. resonant frequency ratio for split inductor Mapham inverters is presented. Next, MIU THD with respect to regulation angle data is presented.

\subsection{Inverter THD vs. fsn}

A Mapham inverter's total harmonic distortion (THD) was characlerized with respect to a frequency ratio $f_{s} / f_{r}=f_{s n}$. The ratio $f_{s n}$ is defined as the inverter swilching frequency, $\mathrm{f}_{3}$, divided by the resonant frequency, $\mathrm{fr}[8]$. Output voltage distortion was measured by two distortion meters, one analog and one digital. The ratio, fsn, was varied by controlling the switching frequency while the resonant frequency was initially thought to be fixed by the values of $L / 2$ and $C$ in Figure 2.2. The results are shown in Figure 5.1. The optimal operating point for a split inductor, unloaded Mapham inverter is a fsn ratio of 0.68 for minimum distortion [9]. The minimum distortion for the unloaded inverter was $1.5 \%$.

It can be seen in Figure 5.1 that the ratio isn exceeds 1.0. In other words, the switching frequency is greater than the resonant frequency which normally would result in commutation failure of the SCRs. In analyzing inductor current waveforms, it was observed that the resonant frequency of a split inductor inverter was not fixed by the tank capacitance, $C$, and leg inductance, $L, 2$. The resonant frequency, as measured by the forward conduction time of the inverter leg currents, increased as the switching frequency increased. This was caused by an overlapping of conduction times for the split inductors, resulting in an effective resonant inductance, Lefl [8]. Therefore, the resonant frequency, $\mathrm{fr}$, is a function of the switching frequency, fs, and load. Various methods for calculating Leff can be found in Brush et. al. [10].

Distortion was also characterized as a function of load. During this test, the inverter was loaded by a resistive load to about $75 \%$ of full load $(6 \mathrm{~kW})$. Again, the switching frequency was varied and percent distortion measured as a function of fsi ratio. The distortion was higher at all points than the unloaded case and had a minimum distortion of $2.7 \%$ at 0.68 fsn ratio (Fig. 5.2). Figure 5.2 also shows that load tends to flatten the curve resulting in a wider range of low distortion operating points.

\subsection{MIU THD vs. Regulation Angle}

Next, tests were conducted to characterize distortion vs. regulation angle in a loaded and unloaded MIU. The

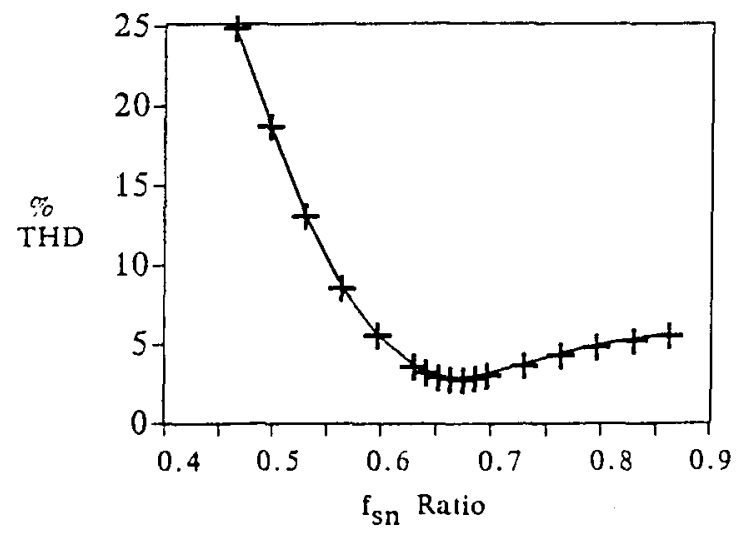

Figure 5.2 - Loaded Mapham Inverter THD vs. $\mathrm{f}_{\mathrm{sn}}$ 
regulation angle (defined in Section 2.1) was adjusted by changing the output voltage setpoint of the MIU. The results for an unloaded MIU are shown in Figure 5.3. The minimum distortion point for an unloaded MIU is at $50^{\circ}$ [8]. For a loaded MIU, the results are shown in Figure 5.4. It shows that distortion increases with regulation angle and the minimum distortion occurs at $0^{\circ}$. These results imply that the optimum MIU regulation angle at full load for minimum distortion is $0^{\circ}$, which is also the optimum regulation angle for maximum efficiency [9].

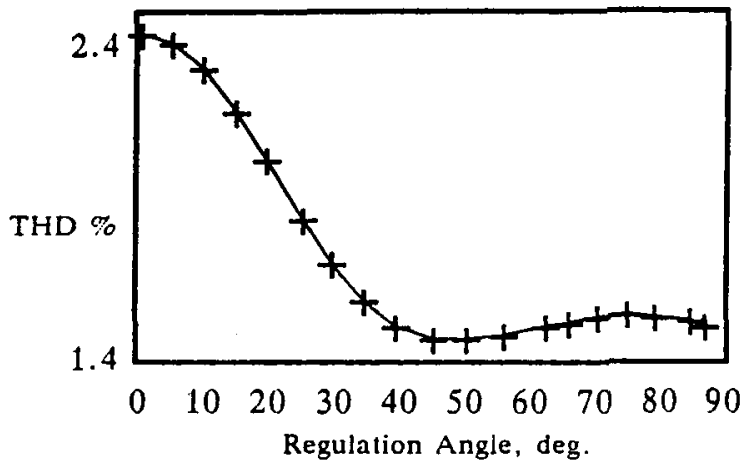

Figure 5.3 - THD vs. Regulation Angle Unloaded Inverter

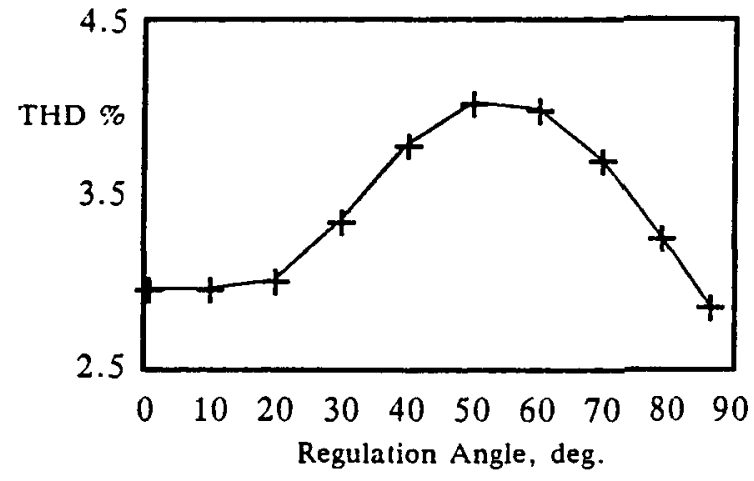

Figure 5.4 - THD vs. Regulation Angle Loaded Inverter

\subsection{MIU PARALLELING TESTS}

In this section, current work on the $20 \mathrm{kHz}$ Breadboard is presented. Initial testing has shown that power sharing between paralleled MIUs can be controlled using two methods. Currently, voltage magnitude control is available by changing MIU output voltage setpoints from the Macintosh computer interface. Circuitry to control the clock phase to each MIU is in work. Results of preliminary testing are given below.

\subsection{Real Power Sharing vs. Voltage Magnitude}

Power sharing between two paralleled MIUs with respect to their output voltage magnitudes was characterized. The parameter which controls the output voltage magnitude is the regulation angle. The regulation angle of each MIU was measured and the output power of each MIU plotted against the regulation angle difference between them. As one MIU's vollage magnitude is varied, the MIU with the lower vollage produces more of the total output power. In this test, MIU B's output voltage setpoint was first lowered from the Macintosh computer interface, and then MIU A's setpoint was raised. This is shown in Figure 6.1. Theoretically, power should be shared equally when the regulation angle difference is zero. The equal power sharing point of -3 degrees is attributed to slightly different MIU output impedances and different propagation delays through the MIU logic circuits.

\subsection{Real Power Sharing vs. Clock Phase}

Next, power sharing between two MIUs with respect to clock phase difference was characterized. The clock phase angle is the difference between the master clocks of two MIUs. The master clocks are used for switch firing synchronization between paralleled MIUs. Changing the clock phase of one MIU phase shifts the output voltage of the MIU with respect to the other. As one MIU begins to lag the other, the lagging MIU increases its power output while the leading MIU's decreases.

The master clock was replaced by an independent clock source in one MIU. The phase angle between the two MIU clocks was varied and the power output of each MIU recorded. The tolal load was $8.2 \mathrm{~kW}$ resistive load and $2 \mathrm{kVAR}$ capacitive cable load. Results of the test are shown in Figure 6.2. As MIU A's output voltage lead MIU B's output voltage, MIU A's output power decreased. As the clock phase difference increased above +9 degrees, MIU A actually supplied power back to the DC bus (negative power through the MIU).

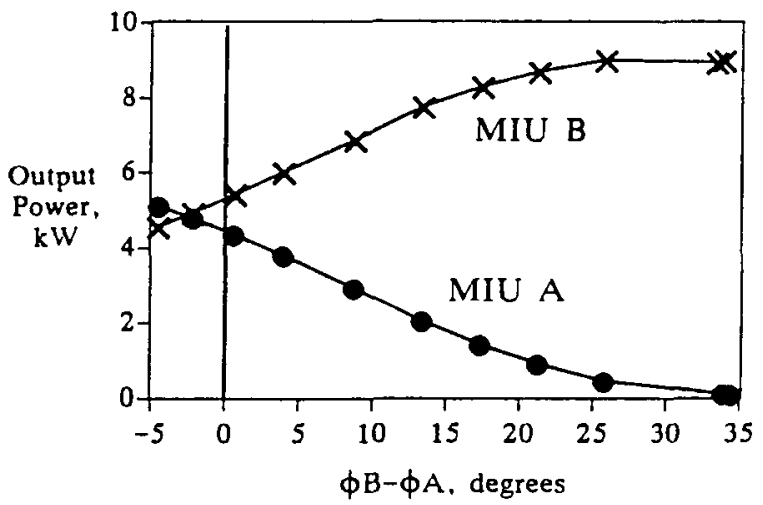

Figure 6.1 - Power Sharing vs. Reg. Angle Difference

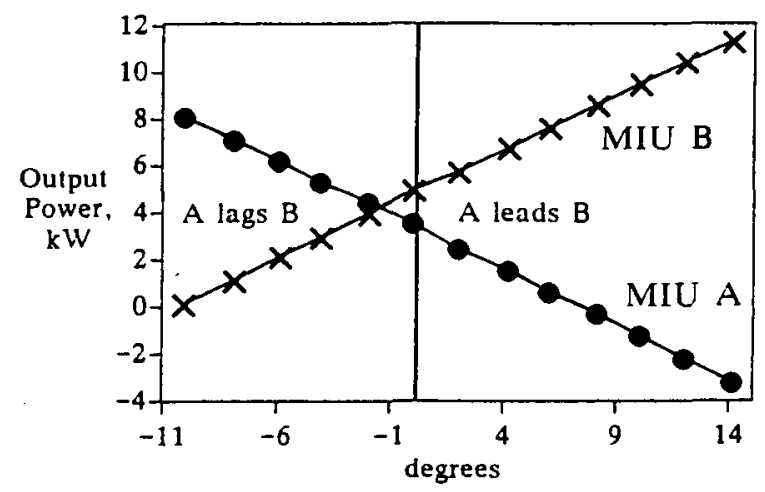

Figure 6.2 - Power Sharing vs. Clock Phase Difference 


\subsection{CONCLUSIONS}

It has been shown through lests of a $20 \mathrm{kHz}$ Breadboard, that a $20 \mathrm{kHz}$ power distribution system is feasible and is expected to meet or exceed current requirements for the Space Station Freedom Electrical Power System.

Power losses in an MIU were apportioned to various inverter components. The power switches (SCRs) and their associated snubber circuitry contributed to over half of the total power losses. Current work with advanced MIUs using high power transistors, low loss snubbers, and improved magnetics have shown increased efficiencies.

An optimum inverter operaling point for minimum distortion was found. Using a switching frequency to resonant frequency ratio of 0.68 will minimize the inverter's total harmonic distortion. Also, an effective resonant induclance value, Leff, was identified.

Lastly, initial tests were conducted to quantify power sharing between paralleled MIUs. Currently, modifications to the $20 \mathrm{kHz}$ Breadboard are under way to incorporate the various power sharing lechniques.

\section{REFERENCES}

[1] "Space Station Power System Preliminary Analysis and Design Document", Rocketdyne Division, 30 June 1986.

[2] D. Renz, "Power Components for the Space Station $20 \mathrm{kHz}$ Power Distribution System", 23rd Intersociety Energy Conversion Engineering Conference, Denver, $\mathrm{CO}$, August 1988.

[3] J. Mildice and R. Sundberg, "AC Power System Final Report", Genera] Dynamics Space Systems Division, NASA CR175068, Nov, 1988.

[4] F. Wolff, "Acceptance Test For A $20 \mathrm{kHz}$ Test Bed", NASA Lewis Research Center, Electrical Systems Division, Oclober 1987.

[5] N. Mapham, "An SCR Inverter with Good Regulation and Sine-Wave Output", IEEE Transactions on Industrial General Applications, Vol. IGA-3 Mar./Apr. 1967, pp. 176-187.

[6] M. Patel "High Frequency Power Distribution System", Induction General, Inc., Contract \#NAS3-23894, April, 1986.

[7] "Main Inverter Unit Efficiency Test Report Phase II". General Dynamics Space Systems Division, Rpt \# 8721-88-021, May 1988.

[8] R. Sundberg, A. Brush, and A. Patterson, "Main Inverter Unit Test Report", NASA Lewis Research Center, Space Station Freedom Directorate PIR $\# 220,11 / 2 / 88$.

[9] R. Sundherg, et. al., "Distortion And Regulation Characterization Of A Mapham Inverter". 24th Intersociety Energy Conversion Engineering Conference, Washington, D.C., August 1989.

[10] A. Brush, R. Sundberg, and R. Button, "Frequency Domain Model For Analysis of Paralleled, Series Paired Mapham Inverters", 24th Intersociety Energy Conversion Engineering Conference, Washington, D.C., August 1989. 


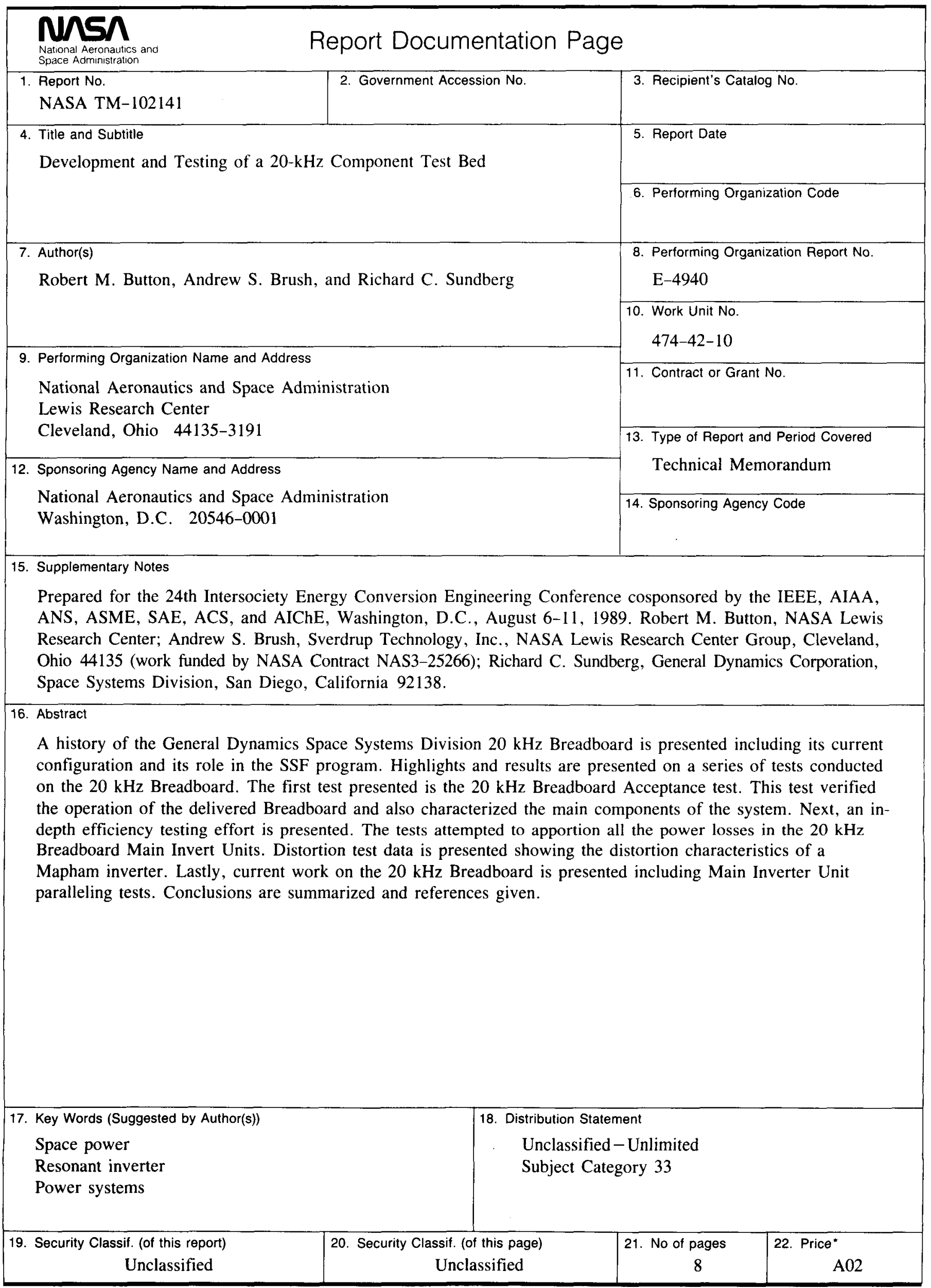

